\title{
OS ASPECTOS DOS DESASTRES SOBRE A ÓTICA DA SOCIEDADE DE RISCO
}

\author{
Clayson Marlei Figueiredo ${ }^{1}$
}

\begin{abstract}
Resumo
Um dos principais efeitos do progresso tecnológico é a submissão das pessoas e do meio ambiente às ameaças. Ao contrário do que se pensava na sociedade moderna, a geração de novos conhecimentos e de desenvolvimento não trouxe um maior controle dos riscos. Para a sociedade de risco, as ameaças sociais, políticas, econômicas e individuais estão escapando dos mecanismos existentes para manter a proteção da população, ultrapassando as fronteiras do tempo e do espaço. Este trabalho aborda os principais aspectos relacionados aos riscos e desastres, do ponto de vista da sociedade de risco, como ameaça, mitigação, precaução, prevenção, vulnerabilidade, percepção de risco, tecnologia, educação científica, análise de risco, leigos, peritos, política, subpolítica, etc. Por fim, faz uma análise dos potenciais e desafios deste conceito de sociedade.
\end{abstract}

Palavras-chave: sociedade de risco. vulnerabilidade. percepção de risco. ciência e tecnologia. proteção e defesa civil.

\begin{abstract}
One of the main effects of technological progress is the submission of people and the environment to threats. Contrary to what was thought in modern society, the generation of new knowledge and development did not bring greater control of risks. For the risk society, social, political, economic and individual threats are escaping from the existing mechanisms to maintain the protection of the population, beyond the borders of time and space. This work addresses the main aspects related to risks and disasters from the point of view of risk society, such as threat, mitigation, precaution, prevention, vulnerability, risk perception, technology, scientific education, risk analysis, lay people, experts, politics, subpolitics, etc. Finally, it analyzes the potentials and challenges of this concept of society.
\end{abstract}

Key words: risk society. vulnerability. risk perception. science and technology. civil defense and protection.

1 - Mestrando em Defesa e Segurança Civil (UFF). Engenheiro civil da Coordenadoria Municipal de Defesa Civil de Rio das Ostras/RJ. (claysonfigueiredo@gmail.com) 


\section{INTRODUÇ̃̃̃O}

Dando continuidade ao processo crescente no período centenário anterior, a racionalidade atingiu seu apogeu no século $\mathrm{XX}$, aliando a noção de evolução tecnológica ao conceito de desenvolvimento humano. O otimismo e a confiança no progresso através da ciência ergueram uma ideia social tendo esta como provedora do bem-estar comum (ANGOTTI e AUTH, 2001).

Não há crescimento ou desenvolvimento se estes não estiverem alicerçados em avanços científicos e tecnológicos, devendo ser igualmente consensual que estes processos precisam estar necessariamente ligados com questões sociais e culturais contextualizadas (BAZZO et al., 2003). Pode-se dizer que esses estudos se caracterizam por reconhecer a complexidade da relação entre ciência, tecnologia e sociedade, se propondo a analisar suas recíprocas influências de forma a superar a simples aplicação da clássica relação linear entre as mesmas. Suas apreciações objetivam superar a tradicional e fragmentada visão acadêmica e inserir o processo técnico-científico no contexto social, fomentando a participação democrática na orientação do seu desenvolvimento (PALACIOS et al., 2005).

Os conceitos de risco vêm sendo discutidos pelos estudiosos há muito tempo, com diferentes focos, considerando características sociais e geográficas, sendo que a primeira os leva por um lado mais subjetivista enquanto a outra num sentido mais objetivista, situando entre estes, outras conceituações com características de ambas. Os estudos também se distinguem pela forma em que encaram as graduações de avaliação, sendo que a maioria enfatiza a escala coletiva, em detrimento da individual, prejudicando as ações de mitigação de risco das políticas de planejamento por não levarem em conta como as pessoas percebem os riscos. Há também uma postura comum que foca em uma análise de tempos e localizações mais definidos, para todas as áreas de risco, não levando em consideração um ponto de vista sociocultural mais amplo (LIEBER e ROMANO-LIEBER, 2002). Entre as diversas abordagens existentes está a análise do risco, que representa uma forma de dimensionar e mitigar os riscos a 
patamares que possam ser absorvidos por uma população resiliente, se apresentando como uma importante ferramenta de análise, que utiliza conhecimento científico e ciência política na tomada de decisões. A partir de problemas empíricos, de reconhecida incerteza, recorre-se a ciência como meio de resolução, não se renegando a necessidade da participação das populações afetadas e do poder público, em concomitância e não em hierarquia.

A sociedade industrial instituiu uma estrutura ideológica endossando o acúmulo de conhecimento e de tecnologias como meios para realizar um mundo mais equilibrado, que seriam capazes de prover a abundância, reduzir a escassez de alimentos, as epidemias, as calamidades naturais etc. Pensava-se que os problemas econômicos eram exclusivos das ciências econômicas, que os problemas de saúde pública eram próprios das ciências da saúde, que os problemas sociais eram específicos das ciências sociais e das iniciativas assistencialistas para consolidar a modernidade e administrar os riscos. Com o fenômeno da globalização nos defrontamos com o desafio da formulação do pensar baseado na complexidade, nos fazendo considerar diversas vertentes que configuram a realidade dinâmica dos fenômenos. Somos contemporâneos de uma variedade de riscos globais com importantes dimensões pessoais (NAVARRO e CARDOSO, 2005).

O fundamento da sociedade de risco, por outro lado se interpõe ao conceito de globalização, democratizando os riscos, atingindo classes sociais e países sem observar fronteiras. Desastres podem ser oriundos destes cenários, onde ameaças como a pobreza em massa, a concentração de riqueza, o crescimento do nacionalismo, do fundamentalismo religioso e das crises econômicas, por exemplo, podem resultar em guerras e catástrofes ecológicas e tecnológicas.

\section{A SOCIEDADE DE RISCO}


Segundo Ulrich Beck (1997), o idealizador da sociedade de risco, a industrialização é inseparável do processo de produção de riscos, pois um dos principais efeitos do progresso tecnológico industrial é a submissão das pessoas e do meio ambiente às ameaças. Os riscos são acompanhados da produção e da distribuição dos bens vindos da industrialização e do incremento científico. Ao contrário do que se pensava, a geração de novos conhecimentos e de desenvolvimento não trouxe a redução das ameaças nem a mitigação ou um maior controle dos riscos. A sociedade industrial, definida pela produção e compartilhamento de bens, foi substituída pela sociedade de risco, na qual a divisão dos perigos não corresponde às diferenças sociais, econômicas e geográficas idealizadas naquela, uma vez que o progresso tecnológico não consegue prever e conter os riscos por ele criado e que geram graves decorrências para o homem e o meio ambiente, ignoradas até então. Por não serem conhecidas, se tornam ainda mais perigosas, como as ameaças nucleares, químicas, ecológicas e genéticas. A confiança nos domínios oferecidos pela ciência teve sua base na modernidade clássica onde os riscos eram entendidos como conhecidos e restritos a determinados contextos, e mesmo que extrapolassem, seriam resultados do avanço tecnológico. Enquanto que na sociedade de risco, as ameaças ultrapassam as fronteiras do tempo e do espaço, sendo oriundos do descontrole da produção industrial (CASTIEL, 2001). O que distingue é a imagem do desenvolvimento tecnológico dentro do cenário do risco, deslocando-o da ordem para a dúvida, ou seja, ao ampliar o domínio do conhecimento e da visibilidade, o progresso amplia igualmente o campo da incerteza. Esta teoria veio para dar maior amplitude ao conceito de risco, mas ainda existe uma dificuldade de se promover uma ligação com considerações mais experimentais, prejudicando o diálogo entre as diferentes abordagens que focam em distintas dimensões da realidade, enfatizando a problemática da natureza multidimensional dos riscos e a necessidade de se transcender as fronteiras disciplinares. Para a sociedade de risco, as ameaças sociais, políticas, econômicas e individuais estão escapando do controle dos mecanismos criados pelos órgãos existentes para manter a proteção e a defesa da sociedade. 
Dentro da sociedade de risco, o indivíduo torna-se um ser reflexivo, que deparando com suas próprias ações e omissões, passa a refletir e criticar racionalmente sobre si, a respeito dos efeitos das ações no passado, sobre as situações atuais e a possibilidade de ameaças futuras (BECK et al., 1997). A modernização reflexiva visa compreender o caminho pelo qual as soluções devem ser planejadas, se tornando a fase radical dos princípios da modernidade clássica. Enquanto esta se caracterizou pela confiança no desenvolvimento e no domínio científico-tecnológico, a primeira é o período na qual o avanço da ciência e da técnica não consegue controlar e prever as ameaças que ajudaram a criar. $\mathrm{O}$ cenário de re-conceituação das interações entre sociedade, ciência e tecnologia, onde a atenção aos riscos prepondera sobre os pretensos benefícios, resulta na tomada de consciência por parte do público, com a finalidade do aparecimento de mecanismos para minimizar os efeitos de viver num estado de incerteza. Os estudos sobre percepção de risco têm evoluído para auxiliar as análises elaboradas em vários campos do conhecimento através deste conceito, levando-se em conta que com os contextos reflexivos constituídos pelos impactos da perspectiva do risco, novos padrões cognitivos se formam, orientando as tomadas de decisões, desde as mais amplas no âmbito institucional às mais cotidianas na vida das pessoas.

A avaliação do risco é estimar o risco e a gestão do risco significa a mitigação ou controle para um nível "aceitável". Tal postura apresenta não apenas a esperança de domar a incerteza, mas também de assegurar a ação política através do conhecimento científico. Assim surgiu o conceito de análise do risco. Rowe (1989) define seu conceito da análise de risco, como uma ferramenta de análise política que utiliza uma base composta do conhecimento científico e da ciência da informação política para subsidiar a tomada de decisões. A análise do risco é, portanto, um auxílio para a teoria da decisão, sua importância e utilidade é resultado de suas aplicações e do sucesso das decisões envolvidas. Estes estudos estão fortemente comprometidos com a visão objetivista, entendendo que a identificação, a avaliação e a gestão do risco podem diminuir a incerteza que convivemos diariamente. 
Embora distintos, o conceito de percepção de risco vem frequentemente ligado à definição de análise de risco, como forma de enriquecer a teoria elaborada para esta que tem um comprometimento com a visão objetivista como modo de redução das incertezas. A objetividade que se pretende dar aos indicadores geralmente compromete a importância do processo cognitivo que labora a percepção de risco, fenômeno que se processa com a concorrência da autopercepção que por sua vez está integrada a um determinado contexto coletivo que abrange a perspectiva comportamental, associada também aos fatores pessoais relacionados à capacidade da formulação cognitiva, aos aspectos afetivos e biológicos e as possibilidades de leitura e de interação com o ambiente externo. Assim, enfrentar ou não situações, observando nelas a perspectiva do risco, dependerá do contexto que posiciona o individuo em um determinado lugar, ou seja, sua inserção em um dado evento (cotidiano ou esporádico), da função que ocupa o indivíduo em determinado espaço social, dos aspectos culturais, da personalidade, da história de vida, das características pessoais e das pressões e/ou demandas do ambiente (NAVARRO E CARDOSO, 2005).

A análise e a percepção de riscos têm pressupostos diferentes. Em geral existe uma incongruência entre a avaliação de certos eventos acontecerem e a percepção das pessoas sobre eles. Enquanto a percepção das pessoas é tida como sem discernimento, considera-se que os cientistas têm condições de dimensionar com exatidão os riscos aos quais tal população está submetida. As pessoas têm também percepções distintas em relação às tecnologias diferentes, sendo necessário entender tal dinâmica para a implantação de políticas públicas adequadas para a implementação de novas tecnologias. Os estudiosos consideram demasiadamente a matemática do risco em detrimento de investigações mais aprofundadas das ações humanas.

Segundo a sociedade de risco é preponderante estabelecer a diferença entre o risco e a percepção do risco. Considera o risco como um procedimento analítico vestido de certa objetividade, por outro lado a percepção de risco admite amplamente a subjetividade, colocando em termos relativos os sentimentos. A percepção desfocada dos riscos pode fazer com que o indivíduo, ao contrário de ser capaz de identificar os 
riscos do mundo, passe a ver a vida com terror, consequentemente, ficando inerte para a ação. A maior ameaça neste caso não é o risco, mas a percepção do risco, que liberta fantasias de perigo, roubando dessa maneira a liberdade de ação da sociedade moderna (BECK, 2001).

A percepção de risco, tem sido abordada com maior amplitude e de uma forma mais subjetivista com o auxílio da antropologia e da sociologia. Entretanto, são nas chamadas ciências da Terra que os conceitos de percepção de risco estão se ampliando, buscando uma maior compreensão para os perigos. Isto porque, mesmo representando umas das mais relevantes correntes de estudo, com vastos estudos experimentais, prescindem de evolução conceitual, entretanto. Como exemplo estão os riscos referentes a geomorfologia, com diversos estudos nesta área, representando eventos natuaris dentre os quais mais causam danos ao homem, ficando atrás apenas das inundações e terremotos, abordando principalmente uma relação das características intrínsecas dos sistemas ambientais, como a vulnerabilidade, ligando-a ao risco, que é resultante da relação de influências exógenas. Por outro lado, estudos com bases predominantemente teóricas, muito desenvolvidos no Brasil, embora tentem interpretar a influência do homem nos sistemas, acabam por fazer uma abordagem estritamente biofísica. Em razão disso a ONU vem tentando desmistificar o fatalismo em relação aos desastres naturais, fomentando a determinação política para o uso de todo o conhecimento existente como forma de mitigação dos riscos. Nesse diapasão, vem surgindo nos últimos anos, trabalhos elaborados por demógrafos, que vem estudando os "riscos naturais", porém com um foco diferente, tentando-se identificar onde acontecem os fenômenos causadores e entender as características sociais que expõem certas populações, podendo ser de determinados extratos sociais, aos perigos resultantes, sendo assim considerando não só a questão social, mas também os aspectos físicos.

As diferenças entre as abordagens são esperadas e são reflexo principalmente da multidisciplinaridade da matéria, mas o que se requer é o intercâmbio do saber e o aprofundamento dos conceitos para melhor entendimento e mitigação dos riscos aos quais as populações estão submetidas. O conceito de sociedade de risco delimitou seu 
espaço dentro das ciências sociais que já estavam discutindo a importância dos aspectos culturais no dimensionamento e no conhecimento em torno do perigo, provocando nesta, como principal mudança, o deslocamento do debate em torno do risco, de tema marginal ao centro da discussão, colocando-o na própria engrenagem social da sociedade atual. Neste moderno cenário social de análise de risco, existe o confronto produzido pelos estudos tradicionais e as teorias que questionam o paradigma do ator racional, colocando em evidência horizontes mais amplos de debate no campo institucional, além de elementos individuais de cunho psíquico.

No entanto, estas mudanças promovidas pelo conceito da sociedade de risco não ocorrem somente no âmbito das ciências sociais, estando presentes cada vez mais em outras áreas, como no direito, enfatizando temas como dano pessoal e o princípio de precaução no direito ambiental e na geografia, no âmbito da problemática ambiental ou em trabalhos mais direcionados, porém existe muito a ser discutido sobre esta questão. Desta análise geral das vertentes de investigação concernente aos riscos, pode-se extrair algumas reflexões. Se por um lado os estudos pautados no objetivismo, que remetem a métodos e técnicas de pesquisa para estudar eventos que ocorrem em um limitado contexto de origem trazem uma aparente solidez por produzir certezas, mas se apresentam como frágeis em um curto período, de outra forma as abordagens mais subjetivistas combatem problemas pertinentes à sua dificuldade em trabalhar em ambientes complexos e dinâmicos, e às incertezas das informações qualitativas e do relativismo. Em ambos os casos, o risco é tratado como uma condição, que dependerá da existência e da relação de uma ameaça e do grau de vulnerabilidade aos quais um sistema está submetido.

Constata-se também que a consideração de aspectos externos agregados aos internos complementa a compreensão de vulnerabilidade, e que se a intervenção do homem realizada de forma imprevista pode trazer incerteza negativa, por outro lado pode causar resultados não vislumbrados de recuperação e resiliência dos sistemas. Importante se faz não acreditar de maneira simplista em relações proporcionais de causa/consequência, compreendendo as complexas interações entre ameaça, 
vulnerabilidade, risco e resiliência, representando uma adequada abordagem sobre as relações de estabilidade e desestabilidade, que na maioria das vezes não estão nítidas e não seguem fórmulas. A sociedade de risco surge neste cenário como ponto de convergência e suporte dos procedimentos usados na avaliação dos riscos, agregando cada vez mais as perspectivas dos estudiosos de outras áreas além daquelas vinculadas às ciências sociais, isto porque o cenário é comum a todas estas abordagens, estando todos no mesmo patamar, apesar de posições diferentes, mas como parte de um mesmo sistema. É importante a busca de uma visão menos particularizada e mais congruente, condizendo com o caráter transdisciplinar que o assunto requer (MARANDOLA JR. e HOGAN, 2004).

Os alimentos transgênicos e a clonagem são avanços na área da biotecnologia que se mostram imersos na forma de pensar da sociedade, representando mudanças extremas em nossas tradições. As novas tecnologias nas comunicações alteraram nossa noção de distância e de relacionamento. O controle social da tecnologia representa além de uma necessidade democrática, uma questão ética. As tecnologias necessitam ser absorvidas pelas pessoas através da mecanismos e contextos de tomada de decisões políticas que impeçam novas formas de exclusão social. Tal compromisso deve ser realizado não só através de leis, mas da evolução moral de nossa sociedade (GARRAFA et al., 2000). Melhorar a divulgação científica como instrumento de reflexão sobre a tecnologia e aumentar seu alcance para deixá-la realmente democrática é uma tarefa que só será possível se torná-la um processo coletivo amplo, que envolva instituições de ensino e pesquisa, estudantes e a comunidade.

Ao se perceberem como parte de uma sociedade e se tornarem conscientes de que evoluem juntamente com o progresso desta, as pessoas compreenderão que suas vidas não estão inevitavelmente preestabelecidas pela lógica às vezes cruel do desenvolvimento, mesmo estando expostas e condicionadas ao aumento do uso da tecnologia em seu convívio (ANGOTTI e AUTH, 2001). O desempenho da cidadania pela motivação dos indivíduos de se envolver em decisões da sociedade é um desafio no qual entender e ponderar a prática científica se faz necessário, o que pode ser feito com 
a aproximação entre a educação tecnológica formal e os espaços de divulgação científica, formando pessoas conscientes e atuantes.

$\mathrm{Na}$ atual sociedade de risco, Beck (1999) alega que existem países menos industrializados, que querem ainda alcançar as vantagens da modernização simples, e outros muito industrializados onde vários setores contestam os fundamentos $\mathrm{e}$ os objetivos da modernidade industrial. Estão presentes três tipos de ameaças globais que podem se complementar e se acentuar: A destruição dos ecossistemas, da camada de ozônio, o efeito estufa, a clonagem e os transgênicos; A pobreza, habitação e alimentação precárias; e as ameaças do tipo nuclear, biológica e química, armas de destruição de massas, riscos que aumentam quando vinculados aos fundamentalismos e ao terrorismo privado. O relevante desta classificação é mostrar que os riscos estão permeados por conflitos em torno de questões étnicas, nacionais e de recursos. $\mathrm{O}$ autor coloca também que as sociedades não-ocidentais como reflexo do que serão no futuro as sociedades ocidentais, com implicações tanto positivas (desenvolvimento de pluralismos religiosos, étnicos e culturais) quanto negativas, como a difusão da informalidade e a flexibilização do trabalho, a desregulação de amplas áreas da economia, a perda de legitimidade do Estado, o crescimento do desemprego, o aumento no poder das corporações multinacionais nos índices de violência (BECK, 2014). Outro aspecto que se desenvolve é o de considerar que os processos de modernização teriam se combinado com elementos de contra modernidade, pois surgiram elementos como o nazismo, o comunismo, a industrialização generalizada da guerra, a militarização de diversas formas da vida social.

A sociedade de risco suscita a necessidade de um rearranjo da política que não propagaria conspirações, ou crises, mas uma modificação da própria sociedade moderna. As instituições políticas como parlamentos, partidos, sindicatos coexistiriam com práticas políticas cotidianas, caracterizadas por uma individualização dos conflitos e interesses. Tal individualização não seria sinônimo de isolamento ou solidão, mas processos em que os cidadãos produziriam suas próprias demandas. A política tradicional cederá lugar à medida que as categorias convencionais forem perdendo seus 
préstimos. A subpolítica, considerada como subsistemas políticos compostos por grupos profissionais e ocupacionais, técnicos de empresas, centros de ciência e tecnologia, profissionais experientes, entre outros, diferem-se da política tradicional, por não contemplar agentes presentes nesta e que participariam do diálogo nos diversos temas. Estes agentes colaborarão como sujeitos coletivos e sociais, assim como individualmente. A subpolítica é uma maneira alternativa e complementar de rearranjar o sistema político, através do compartilhamento do poder com coletivos e indivíduos diversos (BECK, 1997).

Em debates complexos como o aquecimento global, clonagem, alimentos transgênicos, por exemplo, se constata que existem discordâncias entre peritos e contra peritos, que geram descrédito nos expertos por parte da população. Propõe-se então que sejam implantadas instituições abertas e transparentes (espaços de conciliação compostos órgãos públicos, empresas, sindicatos, peritos, organizações sociais, entre outros), que conscientizem os cidadãos e alertem as empresas, com o objetivo possibilitar que a sociedade escolha democraticamente com quais riscos deseja conviver, ao contrário de tentar controlar totalmente ou banir as respectivas ameaças. Estes espaços possibilitam tomar medidas de precaução e prevenção, e não promover compulsoriamente e concordância, mostrando mais claramente quem são os ganhadores e perdedores, democratizando e melhorando as circunstâncias da ação política, fomentando sacrifícios mútuos que não pudessem ser evitados (BECK, 1999).

Deve-se analisar, entretanto, os conceitos de democracia das decisões elaboradas pela sociedade de risco, isto porque expertos e leigos podem estar do mesmo lado como atores individuais, em instituições, redes diversas etc., alianças estas heterogêneas, a favor ou contra uma determinada tecnologia e seus potenciais riscos. Guivant e Miranda (1999) esclarecem que o debate tem emergido mesmo com a crise de confiança nos critérios e nas instituições envolvidos na busca da saúde e da qualidade de vida, dada a falta de acordo científico sobre os riscos que acaba estimulando as incertezas do público nas informações científicas e nas instituições que as emitem, muitas vezes contraditórias e desmentidas em tempo acelerado. A teoria da sociedade de risco se encontra diante do 
desafio de traduzir as críticas e propostas em procedimentos operacionais, não só frente a um conflito entre desinformados e peritos, visto que também envolve influências políticas, poder das corporações, problemas éticos, efeitos econômicos diversos etc. Problemas podem ser ocasionados por visões reducionistas tanto do conhecimento leigo quanto do conhecimento perito.

Os países desenvolvidos e industrializados estão cada vez mais evoluídos tecnologicamente na mensuração e controle dos riscos, mas a confiança da população nos especialistas, nas autoridades governamentais e nas instituições responsáveis pela segurança se vê estremecida quando há ocasiões que mostram as deficiências desse sistema de gestão, causando as reações da população e das organizações, levando os governos e as empresas interessadas a declinar (BEARDSWORTH e KEIL, 1996).

Nos países em desenvolvimento, no entanto, a reação contra novas tecnologias e seus possíveis riscos podem surgir de uma coalizão entre diferentes setores de expertos e leigos. Como os recursos técnicos e pesquisadores não estão disponíveis em quantidades suficientes para avaliar e constatar as ameaças, há muito menos imputações destes riscos e, portanto, menos casos de pânicos na população, numa atitude de conformidade e alienação. Dentre as coalizões heterogêneas contra ameaças desconhecidas encontramos atores sociais e entidades que incorporam o tema em um discurso contra a globalização, as multinacionais etc., com premissas baseadas em interesses econômicos e políticos, levantando a bandeira de setores da sociedade que podem ser prejudicados. Estabelecem enlaces com outras esferas que se vestem de uma identificação maior contra os possíveis riscos tecnológicos, como ONGs internacionais, órgãos de representação dos consumidores e promotores públicos federais, mas os argumentos destes se voltam mais para as ameaças à saúde e ao meio ambiente e para defesa dos direitos dos consumidores, diferentemente dos interesses dos primeiros. Reivindicando a rotulagem e a aplicação do princípio de precaução, tais ações visam redefinir as competências e decisões dos órgãos públicos e organizações que defendem o emprego de novas tecnologias com riscos ainda desconhecidos ou menosprezam a existência de ameaças ambientais, por exemplo. Existem ainda agências governamentais 
e grupos de cientistas que destacam sobretudo o nível de incerteza em relação a estes riscos e que aconselham a aplicação do princípio de precaução.

Neste contexto constituem-se coalizões entre vários conjuntos de imperitos e especialistas, seja em grupo ou como indivíduos, que afluem visando diferentes benefícios e motivações, ultrapassando as fronteiras regionais e nacionais. O conceito da sociedade de risco precisa considerar então as peculiaridades das dinâmicas geográficas, com enlaces específicos e cruzados entre grupos de leigos e de experts, e também articulando os que representam as formas convencionais de política com os atores que representam diversas formas de subpolítica, além de definir mais precisamente o que se entende por esta, evitando-se abordagens idealizadas ou generalistas.

\section{CONCLUSÃO}

Ressalta-se neste trabalho que os riscos se recolocam e recompõem a partir do progresso das situações que os originam, alterando sua relevância, sua percepção e seu controle. A cognição que converte a ameaça difusa em risco definido, produz também alternativas para que os riscos sejam tratados como bases de motivação para importantes avanços legais e sociais. A prevenção de riscos habitualmente se baseia na concepção de que as pessoas possuem a aptidão de observar e de prever eventos indesejáveis. A gestão coletiva de risco, desenvolve diagnósticos e ferramentas para lidar com prováveis ocorrências de desastres a serem evitados ou mitigados e condutas saudáveis a serem potencializadas. Para se consolidarem os benefícios advindos do estudo da sociedade de risco é preciso que pessoas comuns, também chamados de leigos, tenham acesso às informações sobre as tecnologias e seus avanços, em quantidade e qualidade adequadas. O fortalecimento de uma população crítica e reflexiva só possível através do nivelamento dos conhecimentos e dos valores que sustentam as ciências, através da divulgação e educação tecnológicas. 
Revista Científica do Corpo de Bombeiros Militar de Pernambuco

XVIII Seminário Nacional de Bombeiros - Foz do Iguaçu PR

Vol.04 No11 - Edição Especial XVIII SENABOM - ISSN 2359-4829

Versão on-line disponível em: http://www.revistaflammae.com.

Nos conceitos da sociedade de risco se encontram a valorização da participação coletiva nas tomadas de decisões e uma redução do domínio dos especialistas. Outro aspecto é a amplitude sem limite social e geográfico dos riscos da sociedade moderna. Este argumento considera que todos podem ser submetidos à graves ameaças, posicionando os indivíduos num patamar de paciente, enquanto que o primeiro indica a possibilidade de democratização nas decisões em relação aos riscos aos quais queremos estar sujeitados, como sujeito ativo da subpolítica. No entanto, se a teoria da sociedade de risco permite elaborar diagnósticos, precisa partir de concepção de globalização que leve em conta as peculiaridades regionais e seus resultados na dinâmica mundial dos riscos. Ligada a esta definição de globalização, a proposição incide por vezes em oposições entre leigos e peritos, tendendo a idealizar os primeiros, o que dificulta implantar a proposição de subpolítica.

Mas, preponderante não são os fatos relativos que comprovam ou refutam o conceito da sociedade de risco, sendo decisivo mesmo é a indicação de onde, ao tomar o lugar de velhos argumentos, novas concepções fazem exequíveis programas de pesquisa e outras discussões públicas ao passo que levam luz às circunstâncias e aos antigos problemas, além de processar fundamentos marginalizados por outras teorias.

\section{REFERENCIAL BIBLIOGRÁFICO}

ANGOTTI, José A. P.; AUTH, Milton A. Ciência e tecnologia: implicações sociais e o papel da educação. Ciência \& Educação (Bauru), v. 7, n. 1, p. 15-27, 2001.

]BAZZO, Walter A.; PEREIRA, Luis T. V.; LINSINGEN, Irlan V. Inovação tecnológica ou inovação social. In: XXXI Congresso Brasileiro de Ensino de Engenharia. 2003.

BEARDSWORTH, Alan; KEIL, Teresa. Sociology on the menu: An invitation to the study of food and society. Londres: Routledge, 1996.

BECK, Ulrich; GIDDENS, Anthony; LASH, Scott. Modernização reflexiva. Política, tradição e estética no mundo moderno. São Paulo, Unesp, 1997. 
Revista Científica do Corpo de Bombeiros Militar de Pernambuco

XVIII Seminário Nacional de Bombeiros - Foz do Iguaçu PR

Vol.04 No11 - Edição Especial XVIII SENABOM - ISSN 2359-4829

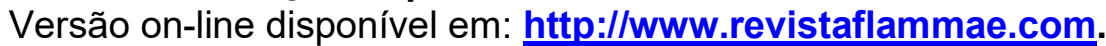

, Ulrich. World risk society. Cambridge, UK: Polity, 1999.

, Ulrich. A ciência é a causa dos principais problemas da sociedade industrial: entrevista concedida a Antoine Reverchon. Folha de São Paulo, São Paulo, p. A12, 2001.

Ulrich. The brave new world of work. John Wiley \& Sons, 2014.

CASTIEL, L. D. A centralidade da regulação na sociedade de risco. Esterisco Home Site, FioCruz. Disponível em:< http://www. ensp. fiocruz. br/projetos/esterisco/suor6. html>. Acesso em 11/06/2018, v. 12, n. 10, p. 2008, 2001.

GARRAFA, Volnei; COSTA, Sérgio Ibiapina Ferreira; OSELKA, Gabriel. A bioética no século XXI. Brasília: Editora UnB, pp. 13-23, 2000.

GUIVANT, Júlia S.; MIRANDA, Claudio. As duas caras de Jano: agroindústrias e agricultura familiar diante da questão ambiental. Cadernos de Ciência \& Tecnologia, v. 16, n. 3, p. $85-128,1999$.

LIEBER, Renato R.; ROMANO-LIEBER, Nicolina S. O conceito de risco: Janus reinventado. MINAYO, Maria C. de S.; MIRANDA, Ary C. de. Saúde e ambiente sustentável: estreitando nós. Rio de Janeiro: Editora FIOCRUZ, v. 15, p. 69-111, 2002.

MARANDOLA JR, Eduardo; HOGAN, Daniel J. O risco em perspectiva: tendências e abordagens. Geosul, v. 19, n. 38, p. 25-58, 2004.

NAVARRO, Marli B. M. de A.; CARDOSO, Telma A. de O. Percepção de risco e cognição: reflexão sobre a sociedade de risco. Ciências \& Cognição, v. 6, n. 1, p. 67$72,2005$.

PALACIOS, Eduardo M. G. et al. Introdução aos estudos CTS (Ciencia, Tecnología e Sociedade). Organización de Estados Iberoamericanos (OEI), 2005.

ROWE, William D. Alternative risk evaluation paradigms. In: Risk analysis and management of natural and man-made hazards. ASCE, 1989. p. 1-21. 